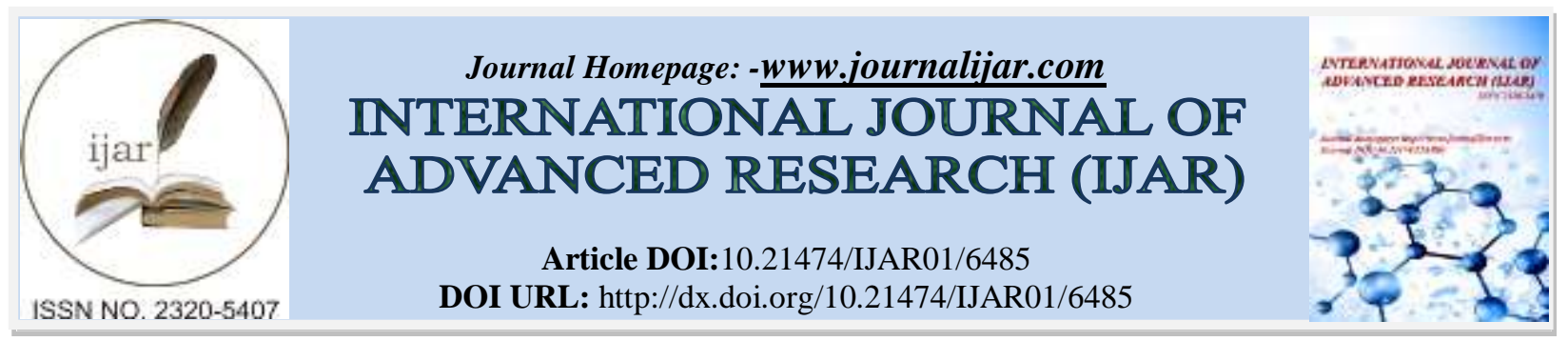

RESEARCH ARTICLE

\title{
THE PREVALENCE OF PERIODONTAL AND ORAL DISEASES AMONG TOBACCO USERS IN UNDERGRADUATE STUDENTS OF HEALTH SCIENCE COLLEGES (DENTAL, NURSING AND PHARMACY) AT UMM AL QURA UNIVERSITY, MAKKAH, SAUDI ARABIA.
}

1. Dental intern, Makkah, Saudi Arabia.

2. General Dentist, Makkah, Saudi Arabia.

3. Associate Professor, Oral Medicine, College of Dentistry, Umm Al-Qura University, Makkah, Saudi Arabia.

\section{Manuscript Info}

Manuscript History

Received: 09 December 2017

Final Accepted: 11 January 2018

Published: February 2018

Keywords:-

Tobacco, Oral Disease, Umm AlQuraUniversity, Students.

\section{Abstract}

Background: With reference to The World Oral Health Organization, tobacco is set to be one of the most horrific causes of disease around the globe considering how widely it is spread in almost all communities and is believed to be to the cause of many oral and systemic illnesses and in many cases it leads to early death.

Objectives: The aim of this study was to determine the relationship between the practice of using Tobacco and oral health (Periodontal and Oral Diseases) among undergraduate students of Health Science Colleges (Dental, Nursing and Pharmacy) at Umm Al Qura University, Makkah, Saudi Arabia.

Methods: The present study was a cross-sectional study, it included 1100 university students from health science colleges (Dental, Nursing and Pharmacy) from the second to the sixth year at Umm Al-Qura University, Makkah, Saudi Arabia.

The hard copy questionnaire was distributed during the lecture time. The questionnaire was divided into two sections: the first section included 2 demographic data attributes (gender and college). The second section included 14 questions asked about (the rule of college in preventing the consumption of tobacco among students, the awareness of students regarding hazards and health damages due to tobacco use, The type of tobacco commonly used by students, the duration of its consumption and frequency, the diseases that might occur due to tobacco use, the effects of tobacco on oral health and their desire of using it or determination to quit it).

The time needed to answer the questionnaire was 5 minutes.

Results: The questionnaire was answered by 900 students out of 1100 (81.8\%). The high percentage of tobacco use belonged to the male students (76.4\%), while for female students it was (23.6\%).

The prevalence of tobacco users among College of Dentistry students was the highest percentage (5\%) Followed by the College of Pharmacy Students (4.5\%) and found to be zero among the students of Nursing college (0\%). 
Most of the students practiced the using of tobacco in order to avoid the stress $(47.6 \%)$ and feel comforted $(64.7 \%)$.

The proportion of people suffering from diseases that affect oral health due to the practice of tobacco use was $(54.1 \%)$. The most diseases that occur due to the practice of using tobacco is the change of the smell of the mouth (50\%) followed by gums and lips diseases (26\%).

The percentage of tobacco users who would like to quit was $(90.5 \%)$. Unconvinced users with laws that the college made against tobacco $(53 \%)$ as well as who neglect efforts and preaching against tobacco $(51 \%)$.

Conclusions: The prevalence of Tobacco Users was high in the students of College of Dentistry and Pharmacy in compared to students of the nursing college.

A high proportion of tobacco users had an impact on their oral health and their most complaints were change in the smell of their mouths.

Health science colleges should make a greater effort to educate and protect their students from falling in the trap of tobacco consumption and help them to quit it in a well-studied manner.

Copy Right, IJAR, 2018,. All rights reserved.

\section{Introduction:-}

There are many bad habits that began to spread around the world among the people and affect their daily lives and cause many diseases that may affect their productivity, work and may lead to the end of their life early, an example of this habits is Tobacco (Petersen PE, 2005).

Tobacco is one of the leading cause of death between people in the developed and developing countries in the world and considered one of the most common causes of death according to World Oral Health Organizing (Sajith Vellappally, 2007).

Each year million people die from Tobacco. Unfortunately this percentage increases year by year. Every year the percentage of people who use tobacco is increasing even if they know its negative effect on their lives. According to WHO, it is considered as an epidemic for it is fast spread and dangerous effect on the people's health (Tjandra Y A, 2006 ; Tomar S, 2003 ; Bernhard D, 2007 and WHO, 2003).

Tobacco causes many systemic diseases including: cancer, coronary heart disease, stroke, peripheral vascular disease and increases the suitability of cancer in many body organs.(Tomar S, 2003 ; Doll R, 1994 ; Peto R, 2000 and Fagerstrom K, 2002).

Tobacco also cause many diseases inside the oral cavity which affect the overall quality of life of the person who practices tobacco. These diseases include: Oral cancer, Staining of teeth and Gingiva, reduction of smell and taste, bad breath and the development of oral diseases such as: Tongue coating, Ulcer, hairy tongue with stomatitis nicotine, development Gingival and periodontal diseases which leads later to the weakening and falling of teeth so the person who is using tobacco appear more old and often complains from his appearance. (Adam T, 2007; Hecht SS, 2006 ; JesperReibel, 2003 ; Mecklenburg RE, 1994 and Christen AG, 1991).

Tobacco uses include different types of this habit as: smoking, water pipe, and sniff chewing. ( Critchley J, 2003) The prevalence of tobacco practice is variable around the world, for example the prevalence of people who practice of using tobacco counts for about $76.2 \%$ in Indonesia (the highest rate in the world) followed by $70.2 \%$ in Jordan and $60 \%$ in Sierra Leone and only $13.1 \%$ in Ghana (the lowest rate in the world). (WHO, 2015).

In Saudi Arabia according to many published studies, the prevalence of people who practice of using Tobacco is between $9 \%$ to 35\% and among university students it is about 13.5\% (Alnohair SF, 2011; Bassiony MM, 2009 and Hashim T, 2000) and among health sector students is about $8 \%$ and more common between dental college students than other health science college's students in many universities in Saudi Arabia. (Agilley A, 2017). 
According to our knowledge there was no previous studies carried out to study the effect of tobacco use on oral health between students of dental, nursing and pharmacy colleges in Umm Al-Qura University. Thus, the aim of the present study is to realize the effect of tobacco use on oral health among undergraduate students of health colleges (Dental, Nursing and Pharmacy) at Umm Al Qura University,Makkah, Saudi Arabia.

\section{Aims:-}

The aim of this study was to Determine the relationship between the practice of using Tobacco and oral health (Periodontal and Oral Diseases) among undergraduate students of Health Sciences Colleges (Dental, Nursing and Pharmacy) at Umm Al Qura University, Makkah, Saudi Arabia.

\section{Methods:-}

The study is a cross-sectional study, investigated students of health science colleges (Dental, Nursing and Pharmacy) from the second to the sixth year of Umm Al-Qura University, Makkah, Saudi Arabia. First-year students and interns doctors and faculty members were excluded from this study.

The questionnaire was distributed to 1100 students from these colleges (450 male, 41\%) and (650 female, 59\%). Students of the College of Dentistry and students of the College of Pharmacy were male and female. Nursing students were only female (The college receives only females).

The questionnaire was distributed during the lectures in classrooms with the assistance of the academic offices in each college and with the permission to distribute it during lectures, to be filled by the students at the end of it. The data collectors were available to help students in answering the questionnaire and collect it after they finished. The questionnaire was divided into two sections: the first section included 2 demographic data attributes (gender and college), The second section is about 14 questions and asked about (the rule of college to prevent tobacco use among students, the awareness of students regarding hazards and health damages due to tobacco usage, The type of tobacco commonly used by students, the duration and frequency of tobacco practice habits, the diseases that might occur due to the usage of tobacco, the effects of tobacco on oral health and their desire of using it or quitting it).

The questionnaire was tested on a pilot group and modified to reach a final version.

The pilot group included 25 students from health science colleges (dentistry, nursing and pharmacy) equally.

The results of the pilot study were excluded from the final study.

The time required to answer the questionnaire was 5 minutes and the study was approved by The Institutional Review Board (IRB) at the College of Dentistry, Umm Al-Qura University.

Statistical analysis: Data was statistically analyzed using SPSS v.17.

A p-value $\leq 0.05$ was considered statistically significant.

\section{Results:-}

The questionnaires were distributed to 1100 students and answered by 900 students (81.8\%).

The questionnaire was answered by 335 males (37.3\%) and 565 females $(62.7 \%)$.

There was a significant difference with a $\mathrm{p}<0.001$ (Chi-square test) in the number of tobacco used between male $((65$ Tobacco Users (19.4\%) and 270 non-Users)) Compared to females ((20 Tobacco Users (3.5\%) and 545 non-Users)).

Table 1:- Compare the number of Tobacco Users (Consumers) in health science colleges

\begin{tabular}{|c|c|c|c|c|}
\hline College & $\begin{array}{l}\text { Tobacco Consumers } \\
\text { No } \%\end{array}$ & $\begin{array}{ll}\text { Non } & \text { Consumers } \\
\text { No } & \% \\
\end{array}$ & $\begin{array}{l}\text { Total } \\
\text { No } \\
\end{array}$ & Significance \\
\hline Dentistry & 455 & $\begin{array}{ll}199 & 22.1\end{array}$ & 244 & $<0.001$ \\
\hline Nursing & 0 & 18220.3 & 18220.2 & $<0.001$ \\
\hline Pharmacy & 404.4 & 43448.2 & 47452.7 & $<0.001$ \\
\hline Total & 859.4 & 81590.6 & $900 \quad 100$ & $<0.001$ \\
\hline
\end{tabular}


Table 2:- Explain the opinion and tobacco experience of students

\begin{tabular}{|l|l|l|}
\hline $\begin{array}{l}\text { Practice of using Tobacco } \\
\text { (consumption) }\end{array}$ & & $\%$ \\
\hline Yes & 85 & 9.4 \\
\hline No the practice of using & 815 & 90.6 \\
\hline $\begin{array}{l}\text { I think ther } \\
\text { Tobacco will affect the oral status }\end{array}$ & 805 & \\
\hline Yes & 95 & 89.4 \\
\hline No the & & 10.6 \\
\hline $\begin{array}{l}\text { Efforts of my college against } \\
\text { practice of using Tobacco }\end{array}$ & \\
\hline Enough 297 & 33 \\
\hline Not enough & 459 & 51 \\
\hline Never & 144 & 16 \\
\hline $\begin{array}{l}\text { My college gives a warning for the } \\
\text { practice of Tobacco use }\end{array}$ & & \\
\hline Yes & 423 & 47 \\
\hline No & 477 & 53 \\
\hline
\end{tabular}

Table 3:-Explain the attitude and behaviour of the Tobacco Users

\begin{tabular}{|l|l|l|}
\hline $\begin{array}{l}\text { Reason for the practice of using } \\
\text { Tobacco }\end{array}$ & Number & $\%$ \\
\hline Against authority & 5 & \\
\hline Pressure relief & 40 & 6 \\
\hline Draw attention & 10 & 47.1 \\
\hline Imitate friends & 30 & 11.7 \\
\hline $\begin{array}{l}\text { Claimed Benefits from Tobacco } \\
\text { Consumption }\end{array}$ & & 35.2 \\
\hline Feeling comforted & 55 & \\
\hline Help to focus & 17 & 64.7 \\
\hline Work stress relief & 13 & 20 \\
\hline Wishes to stop Tobacco consumption & & 15.3 \\
\hline Yes & 77 & \\
\hline No & 8 & 90.5 \\
\hline
\end{tabular}

Table 4:- Explain the attitude of colleges to the practice of using Tobacco

\begin{tabular}{|c|c|c|c|c|}
\hline & Dentistry & nursing & pharmacy & p-value \\
\hline $\begin{array}{l}\text { Tips from college to } \\
\text { reduce and avoid the } \\
\text { practice of using } \\
\text { tobacco }\end{array}$ & & & & \\
\hline Enough & 74 & 125 & 142 & $<0.001$ \\
\hline Not sufficient & 134 & 13 & 308 & $<0.001$ \\
\hline Never & 36 & 44 & 24 & $<0.001$ \\
\hline $\begin{array}{l}\text { Warnings from } \\
\text { college to those who } \\
\text { consume tobacco }\end{array}$ & & & & \\
\hline Yes & 122 & 27 & 185 & $<0.001$ \\
\hline No & 122 & 155 & 289 & $<0.001$ \\
\hline
\end{tabular}


Table 5:- The type of Tobacco consumption, the quantity and the duration of the exercise

\begin{tabular}{|l|l|l|}
\hline & number & \% \\
\hline The type of Tobacco consumption & & \\
\hline Cigarette & 51 & 60 \\
\hline water pipe & 27 & 32 \\
\hline tobacco chewer & 7 & 8 \\
\hline Cigarette rate/day & & \\
\hline less than 10 cigarette & 26 & 51 \\
\hline $10-20$ cigarette & 25 & 49 \\
\hline More than 20cigarette & 0 & 0 \\
\hline water pipe rate/day & & \\
\hline $1-2$ & 25 & 92.6 \\
\hline More than 2 & 2 & 7.4 \\
\hline tobacco chewer rate/day & & \\
\hline less than 10 & 7 & 100 \\
\hline $10-20$ & 0 & 0 \\
\hline More than 20 & 0 & 0 \\
\hline tobacco duration & & \\
\hline less than 1year & 30 & 35.3 \\
\hline 1-5years & 41 & 48.2 \\
\hline 6-15 years & 14 & 16.5 \\
\hline & & \\
\hline
\end{tabular}

Table 6:- The affect of tobacco use on oral health status:

\begin{tabular}{|l|l|l|}
\hline & number & \% \\
\hline Tobacco affect oral health & & \\
\hline Yes & 46 & 54.1 \\
\hline No & 39 & 45.9 \\
\hline Negative impact of tobacco & & \\
\hline Oral and tongue cancer & 1 & 2.2 \\
\hline Change the smell of mouth & 23 & 50 \\
\hline Oral and dental diseases & 5 & 10.9 \\
\hline Diseases of gums and lips & 12 & 26 \\
\hline weakness and falling teeth & 5 & 10.9 \\
\hline
\end{tabular}

\section{Discussions:-}

There are many studies on the usage of tobacco and its effects on oral health in the Kingdom of Saudi Arabia, but there is no study that links tobacco practice with oral health among students of health science colleges at Umm Al Qura University in Makkah, Saudi Arabia.

The questionnaire was answered by 900 students out of 1100.The reason for not answering all the students targeted in the research is the weakness of motivation and low interest from colleges to participate in the research and answering it. (Table1).

In our research, we found that the percentage of the student who practice of using tobacco was 9.4\% (Table2)

This percentage is considered low compared with the proportion of the tobacco users in the community (Peidro CE, 2006).

It may be due to the concern of students and their personal knowledge about the harmful effects of tobacco practice on their general health including oral health.

The percentage of female tobacco users is lower than male and reaches to be $0 \%$ among female nursing students; this may be due to the role of the female's college and the female student's full satisfaction for their college's efforts to control tobacco use (Table4). 
The most common cause of all types of tobacco use is to relief pressure and increase sense of well-being. (Table3).

The most common type of tobacco consumption among students is a inhaling the smoke of cigarettes followed by water pipes. Most of them were newly practicing from one to five years (Table 5).

There is a negative impact of tobacco on the health of students and a large proportion of them suffer from the change of smell of the mouth due to tobacco use and bad oral hygiene between tobacco users (Table 6).

The laws and campaigns that the health science colleges have committed are insufficient and require more work and new plans against tobacco in order to protect their students and keep them away from practicing it in the future as well as helping those who wish to quit.

Health science colleges must provide the healthy environment, relieve the pressure on students, help them to succeed and achieve their goals.

\section{Conclusions:-}

Students of the College of Dentistry are considered the highest tobacco users followed by the College of Pharmacy while in the College of Nursing there is no one committing it.

There are more Males who are tobacco users than females.

Cigarette smoking is the most common type of tobacco usage among students and a high percentage of tobacco users wish to quit.

Health science colleges have to work harder to protect their students from tobacco usage or motivate them in a proper way to quit it.

\section{Acknowledgment:-}

We would like to thank Dr.Shaima Tariq, Dr.Abdulrahman Akbar and Asmaa Agilley for helping in data acquisition. Also, we would like to thank Dr.Hind Abdel-Latif for scientific support.

\section{References:-}

1. Agilley A, Aboalshamat k, Elkwatehy W and Akbar L (2017) ; Smoking Prevalence and Attitude among Health Sector Students in Umm Al-Qura University, Saudi Arabia. International Journal of Advanced Research (IJAR) ISSN 2320-5407

2. Adam T, Baker RR, Zimmermann R (2007) . Investigation, by single photon ionization (SPI)-time-of-flight mass spectrometry (TOFMS), of the effect of different cigarette- lighting devices on the chemical composition of the first cigarette puff. Anal Bioanal Chem.;2:575-84

3. Alnohair SF,(2011); Prevalence of Smoking and its Related Behaviors and Beliefs Among Secondary School Students in Riyadh, Saudi Arabia, Int J Health Sci. 5(1):51-7.

4. Bassiony MM (2009); Smoking in Saudi Arabia. Saudi Med J., 30:876-881.

5. Bernhard D, Moser C, Backovic A, Wick G. (2007) ; Cigarette smoke - an aging accelerator? Exp Gerontol.;42(3):160-5.

6. Christen AG, McDonald JL, Christen JA (1991) ; The Impact of Tobacco Use and Cessation on Nonmalignant and Precancerous Oral and Dental Diseases and Conditions. Indianapolis, Indiana University School of Dentistry

7. Critchley J. Unal B.( 2003) ; Health effects associated with smokeless tobacco : a systemic review. Thorax.;58(5): 435-443

8. Doll R, Peto R, Wheatley K, Gray R et al (1994) ; Mortality in relation to smoking: 40 years' observations on male British doctors. BMJ;309:901-911.

9. Fagerstrom K.( 2002) ; The epidemiology of smoking: health consequences and benefits of cessation. Drugs.;62 Suppl 2:1-9

10. Hashim T(2000); Smoking habits of students in college of applied medical science, Saudi Arabia. Saudi Medical Journal, 21 (1): 76-80. 
11. Hecht SS.(2006 ) ; Cigarette smoking: cancer risks, carcinogens, and mechanisms. Langenbecks Arch Surg.;391(6):603-13.

12. Jesper Reibel(2003) ; Tobacco and Oral Diseases Update on the Evidence, with Recommendations. Med Princ Pract;12(suppl 1):22-32 DOI: 10.1159/000069845

13. Mecklenburg RE, Greenspan D, Kleinman DV, Manley MW et al (1994) ; Tobacco Effects in the Mouth: A National Cancer Institute and National Institute of Dental Research Guide for Health Professionals.

14. Peidro CE, Romero OS, Sala CE (2008); Prevalence of smoking among dentists in Catalonia - Spain. Literature review of smoking cessation practices in the dental office. Med Oral Patol Oral Cir Bucal.,13(10): 671-677

15. Petersen PE, Bourgeois D, Ogawa $\mathbf{H}$ et al (2005) ; The global burden of oral diseases and risks to oral health. Bull World Health Organ . 83: 661-669

16. Peto R, Darby S, Deo H, Silcocks P et al (2000) ; Smoking, smoking cessation, and lung cancer in the UK since 1950: Combination of national statistics with two case-control studies. BMJ;321:323-329

17. Sajith Vellappally, Zdenek Fiala, Jindra smejkalova, Vimal Jacob, et al ( 2007) ;REVIEW ARTICLE : SMOKING RELATED SYSTEMIC AND ORAL DISEASES. ACTA MEDICA (Hradec Kralove) 50(3):161166

18. Tjandra Y A. (2006); Smoking in Indonesia; Jakarta: UI Press, 24-26.

19. Tomar, S. (2003) ; "Is use of smokeless tobacco a risk factor for cigarette smoking? The U.S. experience," Nicotine \& Tobacco Research:; 5(4): 561-569.

20. World Health Organization (2003).The World Health Report: Shaping the Future. Geneva: WHO. http://www.who.int/whr/2003/en/

21. World Health Organization (2015). Prevalence of tobacco smoking, age standardized prevalence of current tobacco smoking among persons aged 15 years and lder.http://gamapserver.who.int/gho/interactive_charts/tobacco/use/atlas.html 